\title{
An innovative approach for generation of a time location plan in road construction projects
}

\author{
Raj Kapur Shah; PhD Student, School of Science and Engineering, Teesside \\ University, UK; Email: r.k.shah@tees.ac.uk \\ Prof. Nashwan Dawood; School of Science and Engineering, Teesside University, \\ UK, Email:n.n.dawood@,tees.ac.uk
}

\begin{abstract}
Existing linear scheduling methods for earthwork activities lack accurate scheduling locations in road construction projects. Project planners and construction managers largely depend on subjective decisions for the allocation of resources at correct locations. This has caused uncertainties in planning and scheduling, and consequently delays and cost overruns of projects. Accurate information of working locations is vital for efficient resource planning, scheduling and equipment mobilisation. In this paper, a theoretical framework for a virtual construction prototype model is developed using the theory of location-based planning and this is used as the basis of sensitivity analysis to identify critical factors affecting road construction. An arithmetic algorithm is developed by incorporating road design data, sectional quantities, variable productivity data, unit cost, site access points, and haulage distance. The model generates a time location plan automatically with the aim to provide location-based scheduling information of earthwork activities. Weekly progress profiles, terrain surfaces, cost profiles and S-curve are the other outputs of the model. Data and information collected from the case studies are used to demonstrate functionalities of the model. Critical factors controlling the productivity of earthwork such as different types of equipment, soil characteristics and site access points were used to display the sensitivity effect by means of "what if scenarios". The paper concluded that the model is a valuable tool in analysing impacts of different factors associated with productivity data and resource planning from location aspects in the earthwork construction projects.
\end{abstract}

Keywords: Earthworks planning, linear scheduling, productivity, time location plan, sensitivity analysis

\section{INTRODUCTION}

Earthwork activities possess unique characteristics, and involve significant costs of haulage between cut and fill sections in a road construction project. These activities also influence the sequencing of the rest of the activities of the construction project (Askew et al, 2002). Planning and scheduling techniques are selected according to the site conditions, and objectives of the construction works. Mass haul diagram, linear programming, optimization model and linear scheduling methods are the key planning and scheduling techniques used in the earthwork operations. The LinearScheduling Method (LSM) is often used in construction projects having repetitive nature like earthworks (Arditi, et al, 1998). 
Previous researchers (Mayer and Stark, 1983; Essa, 1987, 1988; Jayewardene and Harris, 1990) incorporated linear programming techniques to minimise haul distance for earthwork allocation between cut and fill sections in road construction projects. Askew et al (2002) used mass haul diagram techniques for earthwork allocation between cutting and filling sections. Son et al (2002) developed a mathematical optimisation model for the determination of minimum haul distances and directions of the movement of mass earthwork of cutting and filling quantities on a mass excavation projects. However, these studies lack to focus on location-based planning and scheduling, thus not supporting the integration of variables influencing the productivity of earthworks activities.

To address location-based planning; this research presents a prototype of earthwork construction model designed to aid earthwork construction firms for the improvement of space allocation, equipment planning and visualise scheduling information from location aspects. The model generates a time location plan automatically using an innovative methodology for earthwork activities in road construction, whilst providing detailed information of scheduling locations throughout the construction operations. The model is designed to integrate variable factors influencing the productivity of earthwork activities.

The remainder of the paper outlines literature review, design a conceptual framework, develops the theory of the model, and details of the prototype model development that includes inputs, processes and outputs. The outputs of the model are weekly progress profiles, 4D terrain surfaces, cost profiles, production s- curve and a time location plan. This paper also includes an algorithm design for the generation of a time location plan and a case study demonstration with a road project.

\section{Literature review in earthwork planning}

This section outlines previous research studies in planning and scheduling techniques used in earthworks activities to identify possible gaps in knowledge in existing techniques. Unique characteristics of earthworks activities make the planning projects crucial and complex. There are many planning techniques such as mass haul diagram, linear programming, and optimisation model are used for earthworks operations. Mayer and Stark (1983) used linear programming technique to produce earthwork activities aiming to reduce haulage distance between adjacent cut and fill sections. Essa $(1987,1988)$ developed a linear programming model to reduce the cost of earthwork allocation and to minimise haulage distance. This was carried out by integrating non-constant unit cost. The model was enhanced further by incorporating the quadratic model of cost coefficient. Later, Jayewardene and Harris (1990) enhanced the linear programming technique with consideration of project duration and different soil strata, further developing the technique for earthwork optimisation. The above research studies used linear programming techniques to calculating optimal production cost and haulage distance

Furthermore, Alkass and Harris (1991) developed an integrated system for planning earthwork operations in road projects considering the selection of equipment sets. Construction knowledge and experience were captured from planners and equipment specialists to develop a computer program. The program aimed to allocate earthwork 
quantity through the selection of cheaper cost of construction equipment. However, the integrated system lacked to generate a linear schedule and integrate other factors that affect earthwork production schedule.

Additionally, Son et al (2002) developed a mathematical optimisation model for the determination of minimum haul distances and directions of the movement of mass earthwork on a mass excavation project using linear programming. The main inputs of this model were cutting and filling quantities along a road section. The location of the activities and the haulage distances were the outputs of this model; enabling construction professionals to identify the optimal solution to the earthmoving problem. However, this model failed to incorporate different factors affecting earthwork productivity such as equipment sets, site working condition and other constrains at a construction site.

Industry investigation reveals the most common techniques used in earthworks planning are intuitive method, heuristic (thumb rule) and mass haul diagram (Askew et al, 2002). Most of the planning techniques for earthwork operations remain the same regardless of the advancement of construction equipment and evolution of technology for earthwork movement due to the unique characteristics of the earthwork project. The cut-to-fill technique is a fundamental assumption behind earthmoving. This technique reduces the haul distance for filling materials (Askew et al, 2002). The mass haul diagram shown in figure 1 represents cumulative material volume along a linear project.

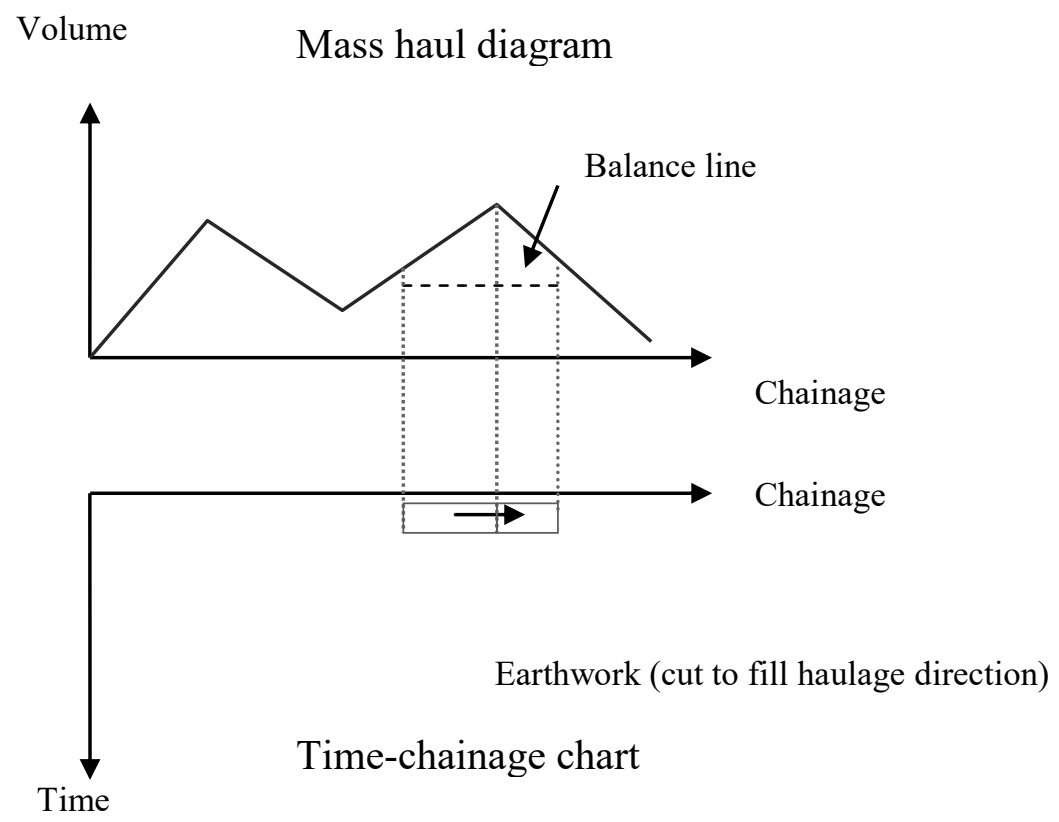

Figure 1 Typical example of a mass haul diagram showing balance line above and a time-chainage chart showing cut to fill haulage direction below

As presented in figure 1, the positive gradients represent cutting sections and negative gradients represent the filling sections. Horizontal lines (balance lines) 
intersecting the mass haul line make equal volumes of cutting and filling sections, as well as minimising haul distances. These balance lines aid in allocation of earthworks activities. However, the mass haul diagram has limitations such as an inability to provide economical haulage distances if the earthwork quantities between cut and fill are imbalanced. It does not incorporate all relevant effects of soil characteristics such as different soil layers at cutting section (Karimi at el, 2006).

Castro and Dawood (2009) developed "RoadSim: a knowledge driven road construction simulation system which has been designed to assist in automating construction high level planning processes and generating accurate road construction plans". The models encapsulate productivity equations and factors influencing the productivity of resources, whilst automating the scheduling works at tender stage. The generated schedule does not support location based plans. However, the "RoadSim" simulation system is used in this research to determine the productivity and unit of the earthwork activities. The focal point of the research is to produce location-based schedule applicable at planning and execution stage considering different factors influencing the productivity of earthwork activities.

\section{Literature review on location-based scheduling}

This section outlines the description of location-based scheduling and identifies the existing linear scheduling techniques used in the linear construction projects such as earthworks in road construction. Line of balance technique is an example of linear scheduling method (Arditi, et al, 1998). This technique is based on the hypothesis that productivity for an activity is uniform. In other words, the production rate (productivity) of an activity is linear when time is plotted on the vertical axis, and location of an activity on the horizontal axis (or vice versa). The production rate of an activity is the slope of the production line, and is expressed in terms of units/linear meter per time (Arditi, et al, 1998).

CPM networks and PERT scheduling techniques are more suitable for complex projects. Whilst linear scheduling methods are more practical for the repetitive and linear projects including road, railway and pipeline (Mawdesley et al, 2004). Scheduling methods including line of balance, repetitive scheduling method, time location matrix model, time space scheduling method, linear scheduling methods, time distance diagram and linear balance diagram are categorized as a „locationbased methodologyee. These methods are based on the theory of location-based planning in the management of construction projects (Kenley and Seppanen, 2009).

Linear scheduling method (LSM) is based on the theory of Location-based planning (Kenley and Seppanen, 2010, p123). This method is important because it provides vital information of actual working locations of activities throughout the construction processes in a bid reduce the dependency on subjective decisions. The precise working locations and timing assist planners/ construction managers in resource planning, mobilization of construction equipment and controlling progress effectively.

The bar chart generally uses the horizontal axis to represent time, showing the start and end date of each activity without displaying location or production rate of the activity. The bar chart scheduling fails to identify potential conflicts of crews, 
location, and time to complete an activity. LSM however, allows identification of the locations of activity and its production rate information (Johnston, 1981).

Johnston (1981) and Garold et al (2005) concluded that linear scheduling technique is a useful technique for planning and monitoring the progress of earthwork activities in a linear construction project. However, existing linear scheduling methods fail to provide exact information of working locations and time throughout the earthwork construction.

Recently, Kenley and Seppanen (2009) identified two types of scheduling methodologies; an activity based methodology and a location based methodology. The location based methodology is also sub divided into unit production and location production. The location-based methodology is an alternative methodology, which is based on tracking the continuity of crews working on production task. Originally, the time-location methodology is a graphical technique. This is based on a technique designed by Adamiecki (1831, cited in Kenley and Seppanen, 2009, p2565) in the early 1900s and was used as a construction management system in 1929s upon the empire state building. This was developed by the Goodyear Company in the 1940s and expanded by the US Navy in the 1950s.

Additionally, DynaRoad (2006) developed commercial software for design mass haul plan, schedule and control the earthwork activities of linear projects. This provided the planning and scheduling information based on location based planning methodology. TILOS is time-location planning software for managing linear construction projects. The aim is to improve the visualisation of repetitive tasks for planning and managing linear projects. TILOS provides the flow of scheduling data in terms of time and place on one plan (TILOS, 2009). However, the existing timedistance chart lacks to provide weekly or daily information of working locations throughout the earthwork operations. This is imperative for resource planning and space-time allocation of earthwork activities. It is also difficult to make decisions for a production schedule due to limited information of working locations and site conditions.

Taking into account previous studies (Johnston, 1981; Arditi et al, 1998, Mattila and Abraham, 1998; Garold et al, 2005; Kenley and Seppanen, 2009, 2010), it concludes that time location plan, which is based on the theory of location-based methodology, is an effective way of representing the planning and scheduling information of earthwork activities in road projects.

The literature review concludes that the time-distance chart is incapable of providing scheduling information of locations. Therefore, this research focuses to investigate an innovative methodology for the development of production schedule showing the weekly information of working locations in a time location chart. The model also incorporates variable factors influencing the productivity of earthwork activities such as sets of construction equipment, soil characteristics and site access points. The model should assist in improving the production scheduling information, which includes sets of construction equipment and weekly information of working locations throughout the earthwork operations. The next section discusses a framework of a prototype virtual construction model. 


\section{FRAMEWORK OF A VIRTUAL CONSTRUCTION MODEL (VCM)}

A general specification of the framework of prototype virtual construction model is outlined in figure 2. The model integrates the road design data, sectional quantities of cutting and filling, "RoadSim" productivity and cost models, algorithms for time location plan visualise in addition to 4D terrain modelling, cost profiles and production s-curve. The model assists in generating time location plan of earthwork process automatically throughout the construction operations.

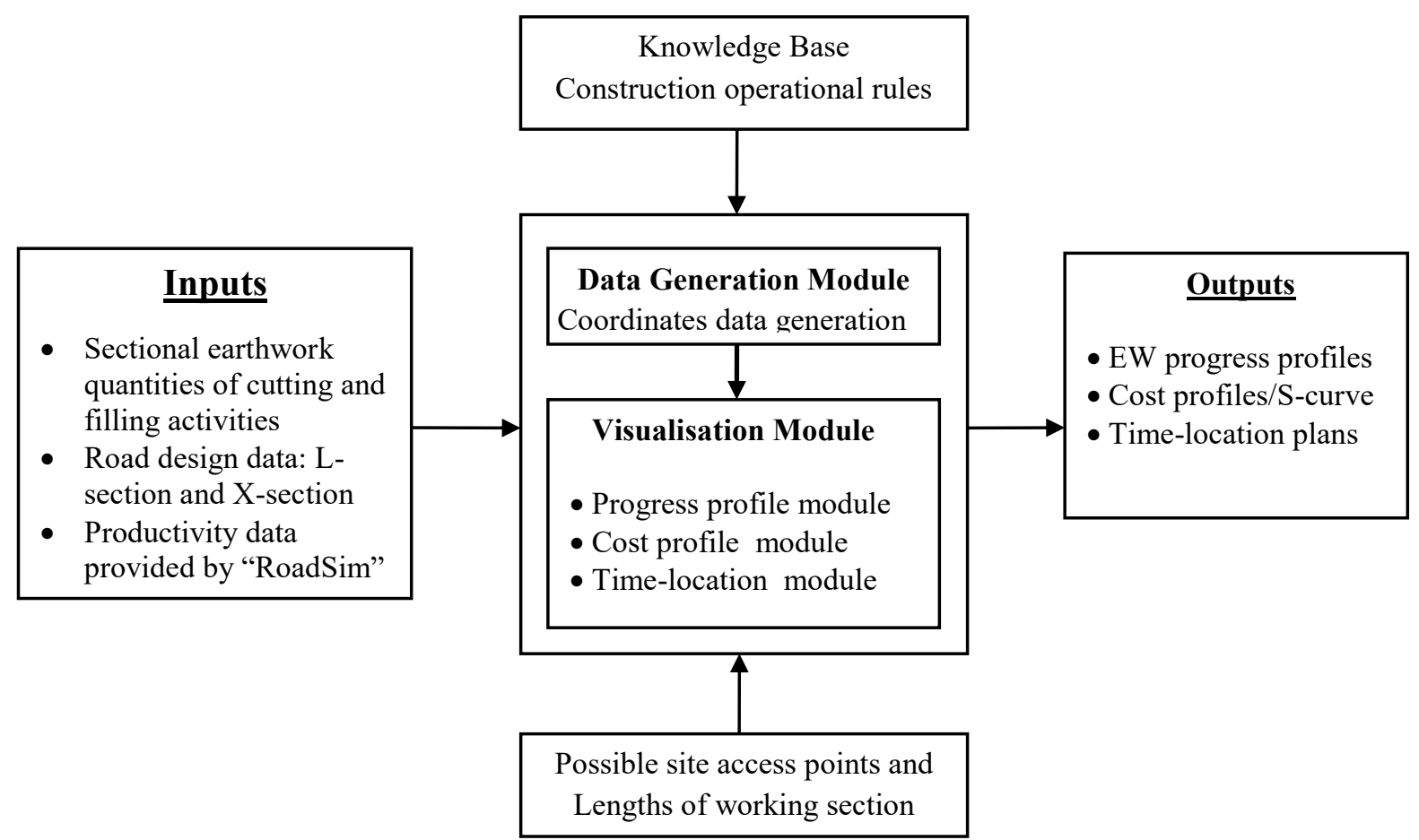

Figure 2 Theoretical framework of a virtual construction prototype model

The research focuses on an innovative methodology, which is introduced for automatic generation of a time location plan aiming to provide the precise working locations information of cutting and filing activities in road construction projects. Although the proposed VCM is capable of generating 4D terrain surfaces of progress profiles, cost profiles and production s- curve, this paper contains the details development of the methodology and algorithms for automatic generation of a linear schedule for earthwork activities, validation with case study and sensitivity analysis of key variables that affect the generated time location plan. The plan is validated with a case study in a road project. The comprehensive explanation of the inputs, processes and outputs of the model are discussed in the following sections. 


\section{Input of the model}

The sectional quantities of cutting or filling activities, productivity and construction site knowledge base are the key components of the model. The cutting or filling quantity at each station is calculated using road design data including longitudinal section and cross sections at required intervals of station (chainage). The productivity data, which is produced by the "RoadSim" simulator, is used as a key input in the model.

The productivity is calculated using available resources, equipment sets and site working conditions. This is incorporated with the model to determine total duration of earthwork operations. The soil characteristics, types of available equipment sets, haulage distance of soil, access road conditions and working efficiency of crew were incorporated within the "RoadSim" simulator. However, earthwork for rock excavation is excluded from this study since the nature of rock excavation id fully different than normal earthwork operations.

Additionally, the model assist in identifying the working locations and numbers of site access points using mass haul diagram. The construction knowledge encapsulated from planner and managers was used to select the construction methods for different types of terrain surfaces and soil characteristics, according to available equipment sets for earthwork operations. The site operational rules and knowledge allow in establishing the sequential relationships amongst listed activities during the construction operations. The following section describes and demonstrates the processes of the model.

\section{Process of the model}

The processes of the framework include four modules; data generation module, visualisation module, cost profile module and a time location module. Data generation module processes the input data as mentioned above to generate the coordinate data of working position of cutting and filling activities incorporating the "variable" productivity data. The time location module processes the coordinate data produced by the data generation module and automates the generation of a time location plan for earthwork activities in road projects. The details of methodology for development of time location plan are presented in the following sections.

\section{Time Location Plan Generation}

Time location plan is a planning tool, which is widely applicable in earthwork planning tasks. The time location plan is also known as time-distance planning, time-chainage planning and linear scheduling method (LSM). It enables the design and display of planning and scheduling information of earthwork activities in two dimensions: Location in $\mathrm{X}$-axis and Time in $\mathrm{Y}$-axis or vice versa together with topographical information of a road project. The slope of activities displayed in time location chart represents a rate of production of the earthwork activities. If the slopes of planned activities are compared with the slope of actual activities, they provide visual information of early indication regarding possible of conflicts or overlap between activities during the course of activity progress. 
The proposed innovative methodology is capable to identify the starting and ending location as well as start and end period of cutting and filling activities at planning stage and the actual information of activities location assist to planner in resources allocation on weekly or daily basis. The methodology is designed with an arithmetical algorithm that identify the locations (stations) along a road section and which are broken down into weekly or daily schedules satisfying the linearity characteristics (start and end locations having equal production rate) of the earthwork activities. The detail derivation of algorithm and mathematical formula used to determine the coordinate of starting and ending location and time of earthwork activities are described below.

\section{Development of Algorithm for Time Location Plan}

An algorithm is designed to identify the coordinates of the working locations considering "variable" productivity of cutting and filling activities. Figure 3 represents a typical longitudinal profile of a road section. AB represents a road section having cutting and filling sections with 11 stations at equal interval (normally 20 or 25 meters are considered in road project). Stations from 1 to 6 represent a cutting section whilst stations from 6 to 11 represent a filling section of earthwork activities excluding rock excavation by blasting.

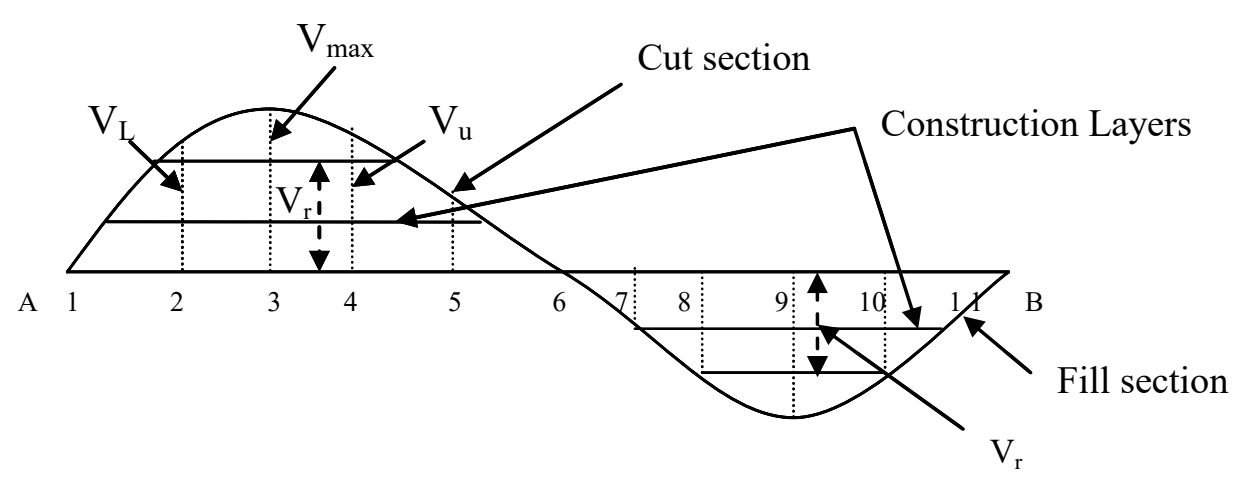

Figure 3 Typical earthwork profiles showing construction layers at cut and fill sections

The details of algorithm development for generation of time location plan are described in the following section. The following assumptions are made for the derivation of the mathematical formula referring figure 3 presented above.

Productivity $(\mathrm{P})=$ Volume (earthwork quantity) at unit time $(\mathrm{t})$

For unit time (t), Excavated earthwork quantity $(\mathrm{V})=$ planned Productivity $(\mathrm{P}) \mathrm{m}^{3} / \mathrm{t}$ Productivity $(\mathrm{P})=$ Total volume of earthwork produced by unit time

Total Volume $(\mathrm{V})$ at each station $=\mathrm{V}_{1}+\mathrm{V}_{2}+\mathrm{V}_{3}+\ldots \ldots \ldots \ldots \ldots \ldots \mathrm{V}_{\mathrm{n}}$

Where $\mathrm{n}=$ number of stations at the section of earthwork operations

Equation 1 cab be expressed as, $\mathrm{V}=\sum_{\mathrm{i}=1}^{\mathrm{i}=\mathrm{n}} \mathrm{V}_{\mathrm{i}}$

Where, Station numbers along a road section $(\mathrm{i})=1,2,3 \ldots \ldots \mathrm{n}$ 
At each station, there are multi layers and the sum of volume of stations at each layer

$\mathrm{V}_{1}=\mathrm{V}_{11}+\mathrm{V}_{12}+\mathrm{V}_{13}+\mathrm{V}_{14}+\ldots \ldots \ldots \ldots . \mathrm{V}_{1 \mathrm{t}}$

Equation 3 can be expressed as $\mathrm{V}_{1}=\sum_{\mathrm{j}=1}^{\mathrm{j}=\mathrm{t}} \mathrm{V}_{1 \mathrm{j}}$

Where; $t=$ number of layers during earthwork operations, $j=1,2,3$............t

Combing the equations 2 and 4 ,

$\mathrm{V}=\sum_{i=1}^{i=n} \sum_{\mathrm{j}=1}^{\mathrm{j}=\mathrm{t}} \mathrm{V}_{\mathrm{ij}}$

At each layer, after performing earthwork activity, there is always remaining volume at each station and each layers, the remaining volume of earthwork is represented by equation 6

Remaining volume at each layer should be equal to $(\mathrm{Vr})=(\mathrm{V}-\mathrm{P}) / \mathrm{n}$

Where; $r$ represents number of layers: $r=1,2,3 \ldots . t$

Substituting the value of $\mathrm{V}_{\mathrm{r}}$ and $\mathrm{V}$ in equation 6:

$$
\sum_{\mathrm{r}=1}^{\mathrm{r}=\mathrm{t}}\left(\mathrm{V}_{\mathrm{r}}\right)=\left[\left\{\sum_{i=1}^{i=n} \sum_{\mathrm{j}=1}^{\mathrm{j}=\mathrm{t}}\left(\mathrm{V}_{\mathrm{ij}}\right)-\mathrm{P}\right\} / \mathrm{n}\right]
$$

Here $\mathrm{V}_{\mathrm{r}}$ is the sum of total remaining volume at each layer of all selected stations between working zone.

Whereas,

$\mathrm{n}=$ number of stations under operation in a road section,

$\mathrm{r}=$ the number of remaining volume at unit time that varies from 1 to $t$,

$\mathrm{t}=$ number of layers during earthwork operations at cut/fill sections

$\mathrm{V}_{\mathrm{r}}=$ the sum of remaining volume after progress at each layer,

$\mathrm{P}=$ productivity of earthwork activities according to cutting/filling sections

$\mathrm{P}=\mathrm{P}_{\mathrm{f}}$ for earthwork productivity in the case of filling operations

$\mathrm{P}_{\mathrm{c}}=\mathrm{Pc}$ for earthwork productivity in the case of cutting operations

The time location algorithm is designed to search a number of stations whose sum of earthwork volume (quantity) is equivalent to the productivity of cutting or filling activities. In this algorithm, the unit of time can be considered as weekly or daily. The algorithm identifies a station having the highest in cutting and lowest in filling at first using lookup function of VBA macro and existing practice in earthwork operations. A flow diagram of designed algorithm for calculation of coordinate data of the starting and ending locations of earthwork activities on a weekly or daily basis is presented in figure 4 . 


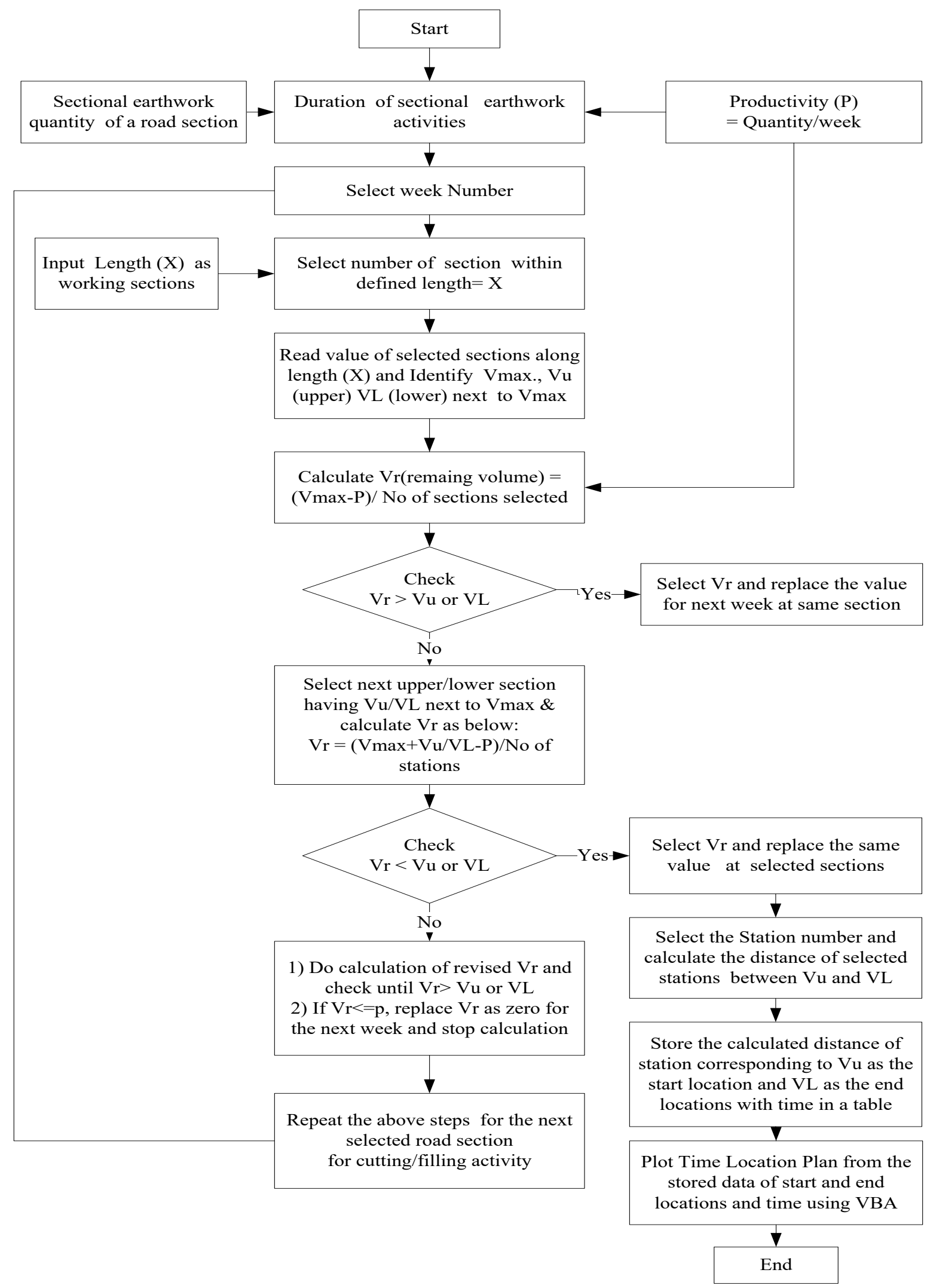

Figure 4 Data flow diagram for automatic generation of a time-location plan 
After identifying maximum or minimum station, the algorithm starts to search nearby stations forward (upper limit station) and backward (lower limit station) from the first station (highest/lowest station according to cutting/filling sections) to satisfy the earthwork quantity equivalent to the planned production quantity using equation 7. The quantity is equivalent to the sum of the volume of all selected stations along a road section. The numbers of working stations are selected in such a way so that the remaining volume of selected stations at unit time $(\mathrm{t})$ remains the same. Equation 7 presented above is used for identification of station number at each layer during earthwork operations by incorporating the „variable ${ }^{\text {ee }}$ productivity data. This process is repeated at each layer of cutting or filling sections to achieve the remaining volume ( $\mathrm{Vr}$ ) at each station is equivalent to zero (at the design level of road) between selected working sections (zone) along a road project.

At each layer, the starting and ending stations are identified and their lengths between the two stations are determined using an algorithm designed and it is coded with the VBA programming language embedded with Ms Excel. These lengths, at each layer between working stations, increase from the first to the last layer at both cutting and filling sections of the earthwork operation. Similarly, cutting and filling sections are selected according to the earthwork schedule to complete the earthwork operations throughout the construction of a road section. If the cutting or filling sections are longer, these sections are divided into manageable sections and the processes above are repeated to achieve the design level of the road.

In this model, two input variables: productivity (p) of earthwork activities produced by "RoadSim" and working zone length (X) determined by "mass haul diagram" were integrated with the model to search the coordinate of starting and ending locations of working section. The algorithm assists to calculate the coordinate of working locations considering "variable" productivity data throughout the construction operations in a road project. Therefore, coordinates of weekly or daily locations directly depends on the value and unit of productivity i.e. weekly or daily productivity by assuming $40 \mathrm{hrs}$ per week or $8 \mathrm{hrs}$ per day as standard working time. The identified coordinate data of locations and time of earthwork activities are stored in a table at first and then exported the coordinate data by programme to generate graphical representation of time location plan. The time location plan has generated automatically.

The generated time location plan provides more accurate information of locations for earthwork planning and scheduling on weekly and daily basis. The time location plan assists to planner and construction managers in allowing the visualisation and analysis of the status of construction activities on a particular location along the road sections.

\section{DEMONSTRATION OF MODEL FUNCTIONALITIES WITH CASE STUDY}

A case study involving $1.0 \mathrm{~km}$ of road section of lot no. 3 road project in Portugal was selected to demonstrate the functionalities of the model. Actual road design data including L - section and X-section is considered, and the sectional quantity of earthwork is calculated assuming typical trapezoidal sections at $25 \mathrm{~m}$ intervals along the selected road section. The productivity data of cutting or filling activities is 
considered as a key factor that affects the construction duration, working locations and numbers of construction layers required to complete earthwork operations.

Since the model outputs directly depend on the accuracy of the productivity data, the case study was run to compare the variation in the productivity value between actual site progress and model used value for earthwork activity. The case study results revealed that the actual productivity value was lower by $2 \%$ compare to the productivity value produced by the model to generate a time location plan for earthworks components in road projects. The outputs of the model are: earthwork progress profiles, 4D terrain surfaces, cost profile, production s- curve and a time location plan for earthwork planning and scheduling. These are discussed briefly and presented in the following sections.

\section{Earthwork progress profiles and 4D terrain surfaces}

The graphical representation of weekly progress profiles and 4D terrain surfaces generated by the model during earthwork construction operations in a road project are presented in the paper. The terrain surface is represented by regular triangulation mesh where $\mathrm{Z}$ coordinate represent the height of the vertex in terrain surfaces, $\mathrm{X}$ direction represents longitudinal section and $Y$ direction represents the cross section of a road. The road surface is represented in terms of height in mesh form. The maximum point of cut and fill section is identified first where construction operations start according to the existing practices and construction site knowledge. The next terrain surface/progress profile is generated by considering the remaining cutting and filling sectional quantity. This is equivalent to weekly production rate after excavating/backfilling earthwork quantity. This operation repeats for the next economical length of the road section where cutting and filling operations take place. The economical length (balance line) has been identified using the mass haul diagram and it is integrated in the model to visualise earthwork quantity allocation between cut and fill sections along the selection road section.

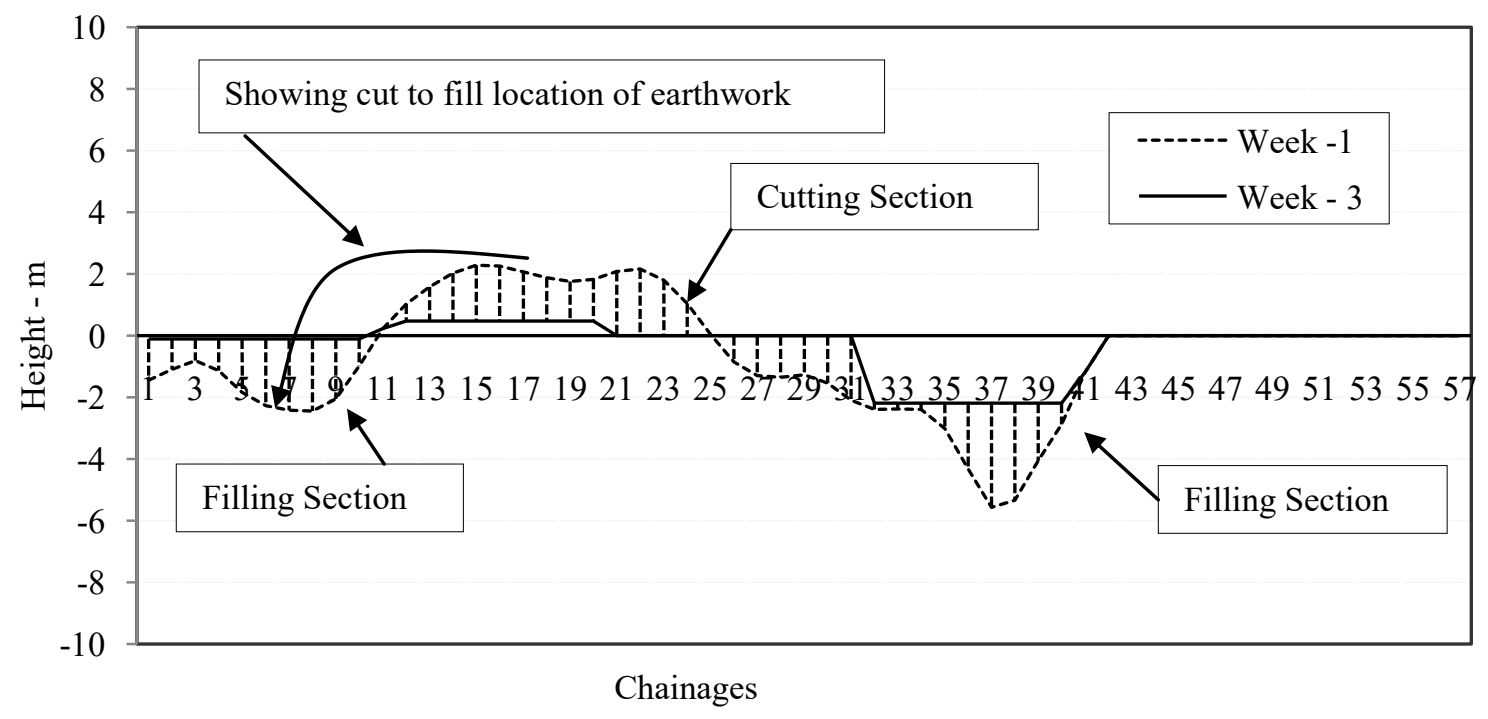

Figure 5 Automatic generated earthwork progress profiles at the end of week 1 and 3 showing a location of hauling direction from a cutting section to a filling section 


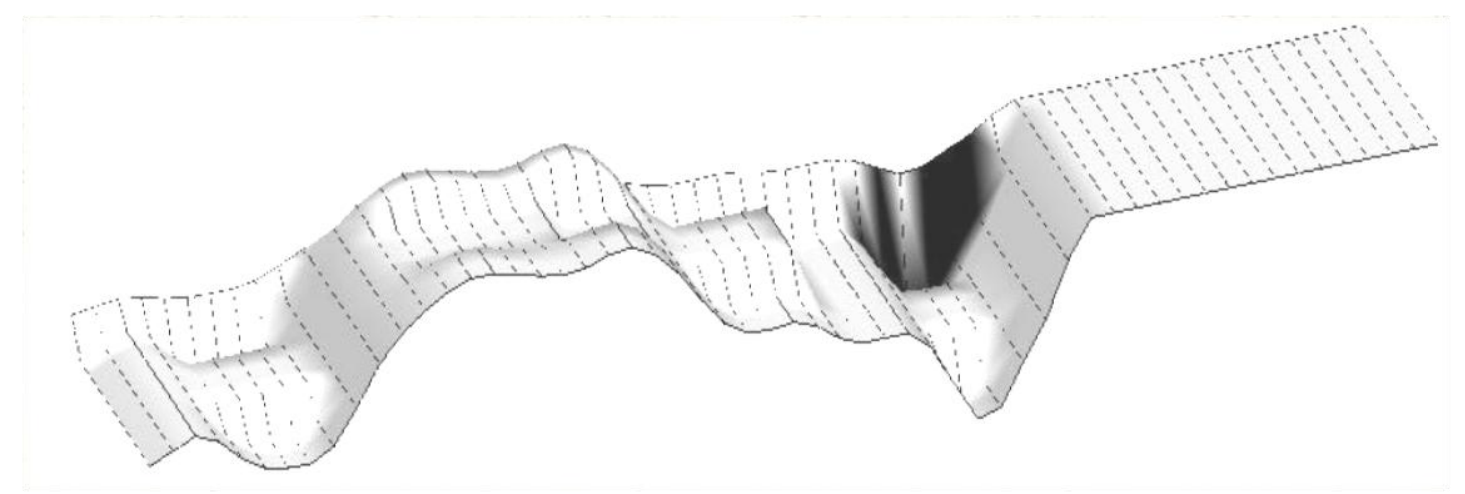

Figure 6 Snapshot of automatic generated ground profile by the prototype model during earthwork construction at the end of week 3

Figures 5 and 6 are the graphical representation of earthwork scheduling information in order to visualise and simulate the distribution of weekly earthwork quantities between cutting and filling sections of a road project. The index shows the depth of filling and height of cutting section in a particular week. The earthwork quantities distribution between cut and fill sections could be changed according to site access points, available resources and equipment sets. This assist in simulating with "what if scenarios" for different alternative route and soil characteristics along the road section so that site productivity can be enhanced and the production cost of earthwork can be reduced. The next section discusses the location based cost profiles and production s- curve.

\section{Cost profiles and production cost $\mathrm{S}-$-curve:}

The developed VCM has additional capability to generate weekly cost profiles at each chainage (station number) along a road section. Using a case study, the generated weekly cost profiles are presented in figure 7. Since, the generated production cost profiles are integrated with productivity data, any variation in productivity data due to soil characteristics, selection of equipment types and site constrains have dynamic impact on production cost profiles. The cost profiles assist to control the location- based production cost throughout the earthwork construction. Additionally, the model also generates production cost S-curve for earthwork operations, which is shown in figure 8. This is useful to control and manage the production cost of the earthwork activities at each location on weekly basis by comparing with actual cost throughout the construction operations. 


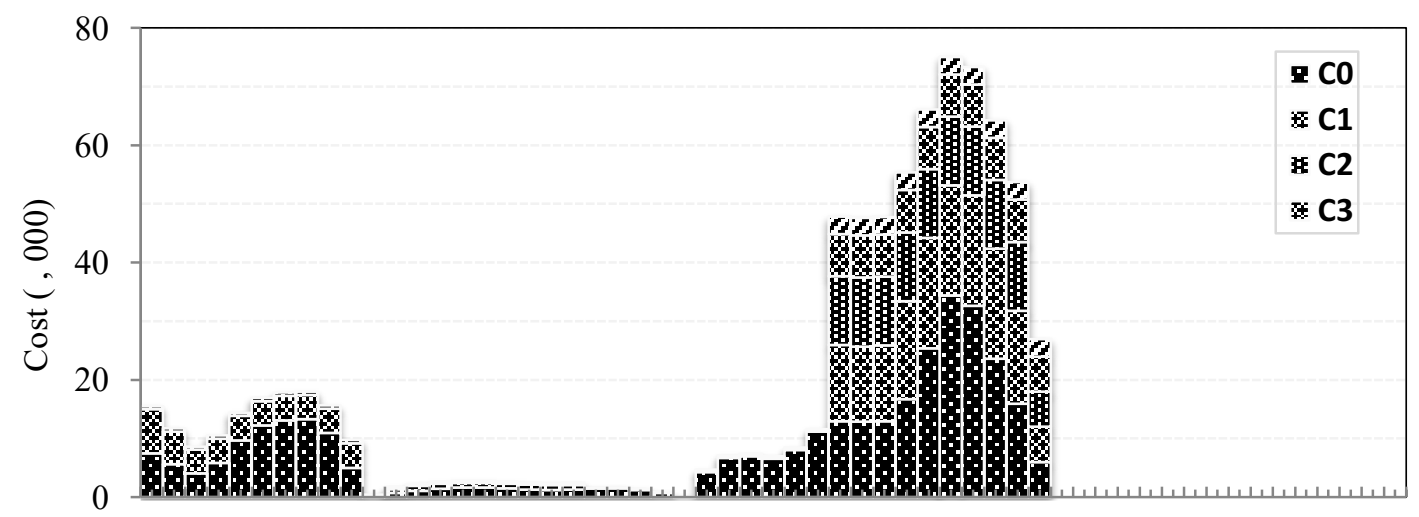

1335799111315171921232527293133353739414345474951535557 Chainages

Figure 7 Snapshot of automatic generated weekly cost histogram at each station of a road section

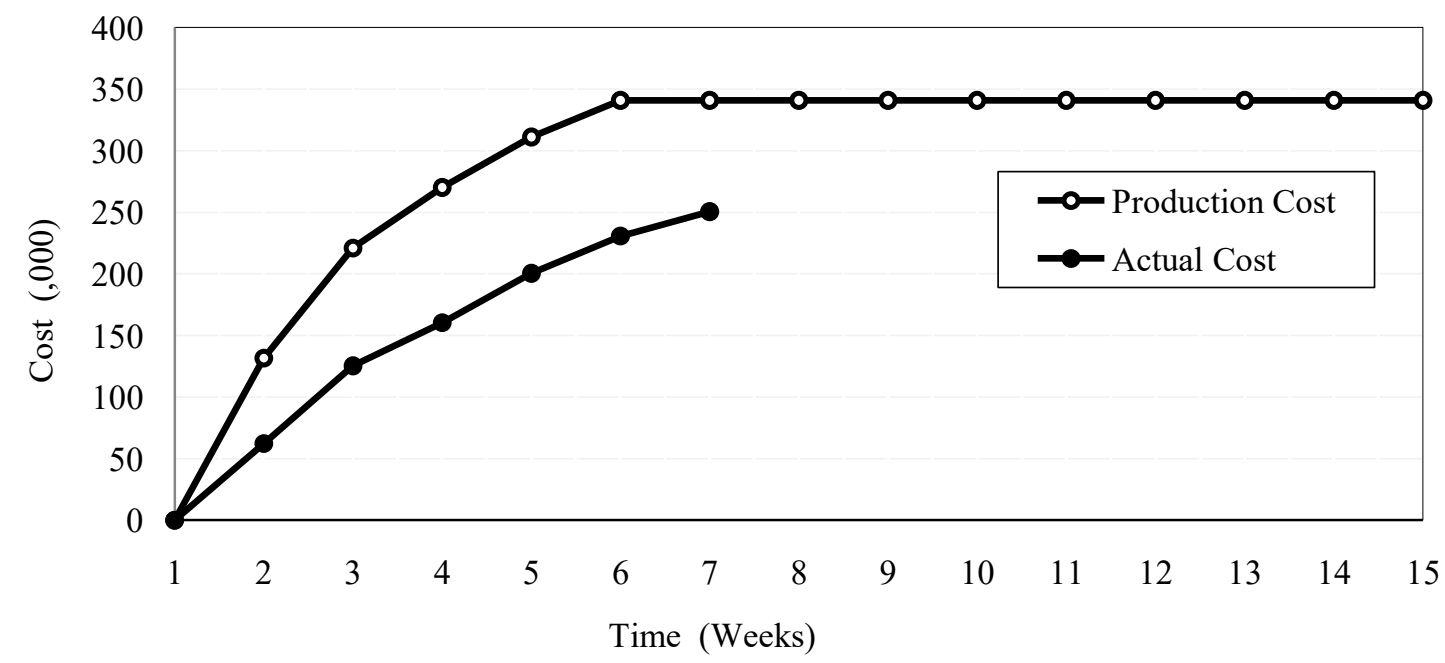

Figure 8 Snapshot of automatic generated cost S-curve of the road section

The next section discusses the methodology for the generation of weekly coordinate data for time location plan of earthworks activities.

\section{Automatic generated time location plan (time - distance diagram)}

The developed VCM also generates a time location plan, which is valuable for earthwork planning and scheduling tool in road construction projects at execution stage. The weekly progress profiles of earthworks for a selected road section are presented in figure 9. This helps to visualise the scheduling information from location aspects and allocate the mass haulages quantities between cut and fill sections. The developed algorithm generates the coordinates of the starting and the ending locations of earthwork activities with corresponding the start and the end date, and produces a list of coordinate data on a table (see table 1). The coordinate data was used to generate a time location plan using arithmetic algorithms and VBA programming and outputs of the model are shown in figures $10(\mathrm{a})$ and $10(\mathrm{~b})$. 
Table 1 Coordinate data of weekly start and end working locations of cutting and filling activities in a road section.

\begin{tabular}{|c|c|c|c|c|c|}
\hline S.N. & $\begin{array}{l}\text { X1 (Start Station) } \\
\text { m }\end{array}$ & $\begin{array}{l}\text { X2 (End Station) } \\
\text { m }\end{array}$ & $\begin{array}{l}\text { Y1 (Start Date) } \\
\text { day }\end{array}$ & $\begin{array}{l}\text { Y2 (End Date) } \\
\text { day }\end{array}$ & Cut/Fill \\
\hline w0 & 125 & 200 & 0 & 1 & $F$ \\
\hline $\mathrm{w} 1$ & 100 & 200 & 1 & 2 & $\mathrm{~F}$ \\
\hline w2 & 100 & 200 & 2 & 3 & $F$ \\
\hline w3 & 100 & 200 & 3 & 4 & $F$ \\
\hline w4 & 0 & 200 & 4 & 5 & $F$ \\
\hline w5 & 0 & 225 & 5 & 6 & $F$ \\
\hline $\mathrm{w} 6$ & 0 & 225 & 6 & 7 & $F$ \\
\hline w7 & 0 & 225 & 7 & 8 & $F$ \\
\hline w8 & 0 & 225 & 8 & 9 & $F$ \\
\hline w9 & 0 & 225 & 9 & 10 & $F$ \\
\hline w10 & 0 & 225 & 10 & 11 & $F$ \\
\hline w11 & 0 & 225 & 11 & 12 & $\mathrm{~F}$ \\
\hline w12 & 0 & 225 & 12 & 13 & $F$ \\
\hline w0 & 325 & 425 & 0 & 1 & $\mathrm{C}$ \\
\hline w1 & 325 & 475 & 1 & 2 & $\mathrm{C}$ \\
\hline w2 & 300 & 475 & 2 & 3 & C \\
\hline w3 & 300 & 475 & 3 & 4 & $\mathrm{C}$ \\
\hline $\mathrm{w} 4$ & 300 & 475 & 4 & 5 & $\mathrm{C}$ \\
\hline w5 & 275 & 475 & 5 & 6 & C \\
\hline w6 & 275 & 475 & 6 & 7 & $\mathrm{C}$ \\
\hline w7 & 275 & 475 & 7 & 8 & $\mathrm{C}$ \\
\hline $\mathrm{w} 8$ & 275 & 475 & 8 & 9 & $\mathrm{C}$ \\
\hline
\end{tabular}

The time location plan was integrated with variable productivity data so that the time location plan can be generated automatically according to any changes in site conditions, access point, equipment productivity and soil characteristics throughout the construction operations.

The number of weeks required for a cutting or filling section is represented by week, for example, w1 (filling at day 1 in black colour), w1 (cutting at day 1 in light black colour) as shown in the index of figures 10 (a) and (b). Figure 10(a) presents earthwork tile location plan using two sets of filling and one set of cutting equipment whereas figure 10(b) shows the plan using one set of filling and one set of cutting equipment. Similarly, the coordinate of starting and ending point of activity is also presented in terms of location and time ( $m$, day). 
The generated time location plan is integrated with variable productivity data of earthwork activity. Any variation in productivity data due to soil characteristics, selection of equipment types, site constrains along the road section have dynamic impact on time location construction plan that assists the planner to control the progress and monitor production cost during planning and construction stage of road projects. The next section describes the sensitivity analysis in total duration of earthwork operations due to the variations in site access points, types of available sets of equipment and soil characteristics along a road project.

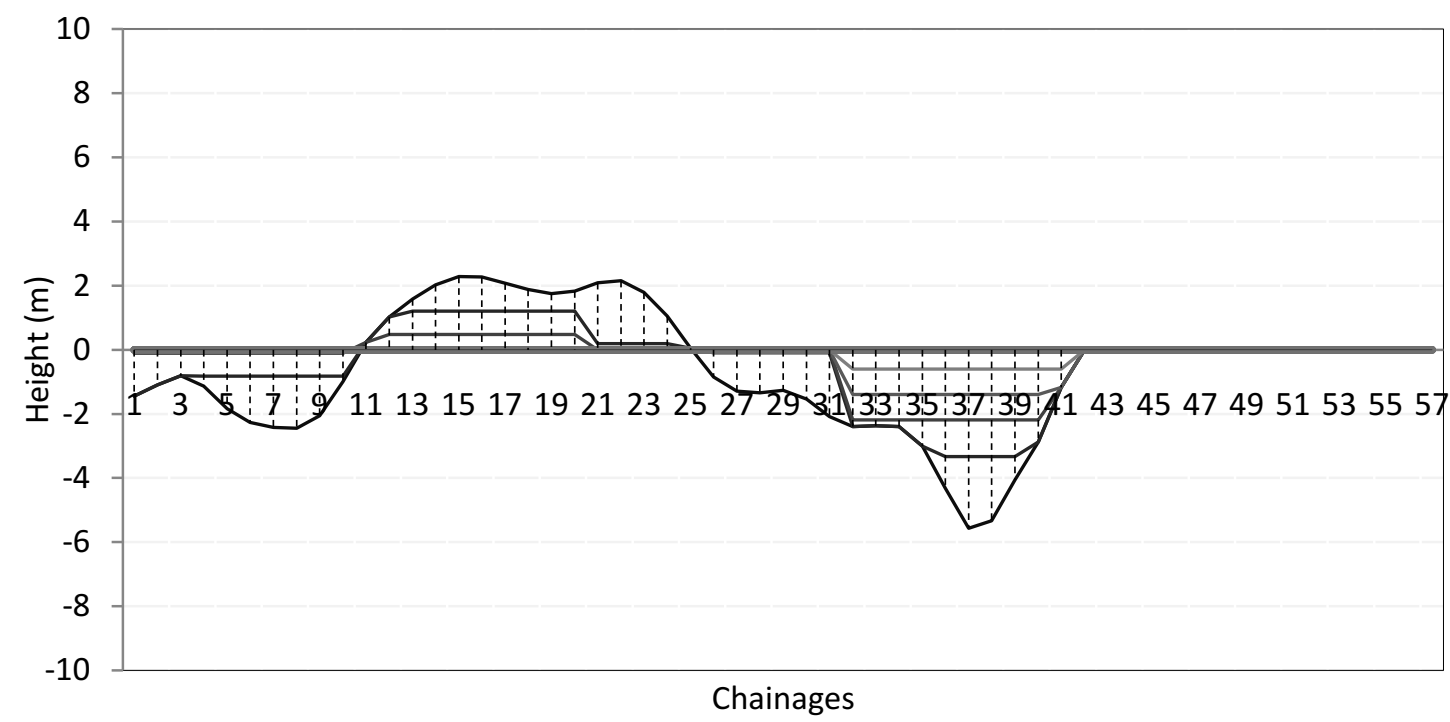

Figure 9 Snapshot of automatic generated weekly earthwork progress profiles of a road section

Figures $10(\mathrm{a})$ is an example of model capability to produce a time location plan considering different sets of equipment working in cutting and filling sections simultaneously in a selected road section. Figures 10(a) and (b) presents the cutting and filling activities with different colour at different locations in day or week. The time location plan was integrated with variable productivity and different working sections in a road project.

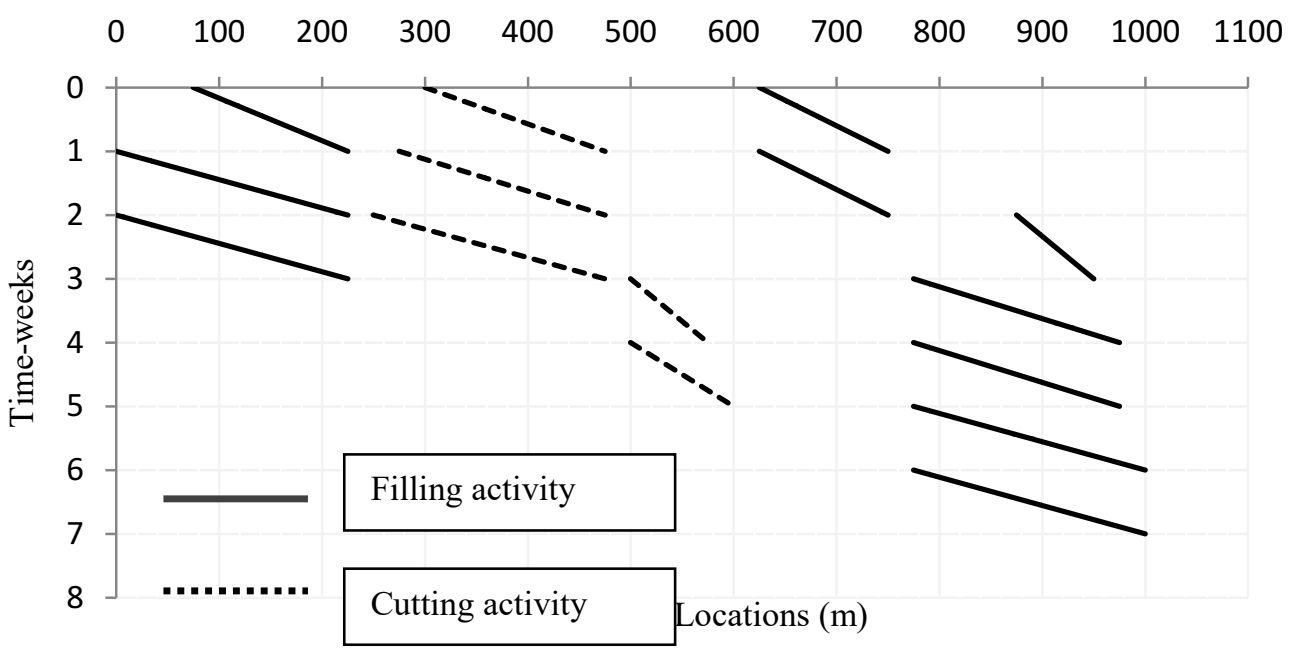


Figure 10a Snapshot of automatic generated time location plan of a road section using two sets of equipment for filling operation and one set of equipment for cutting operation

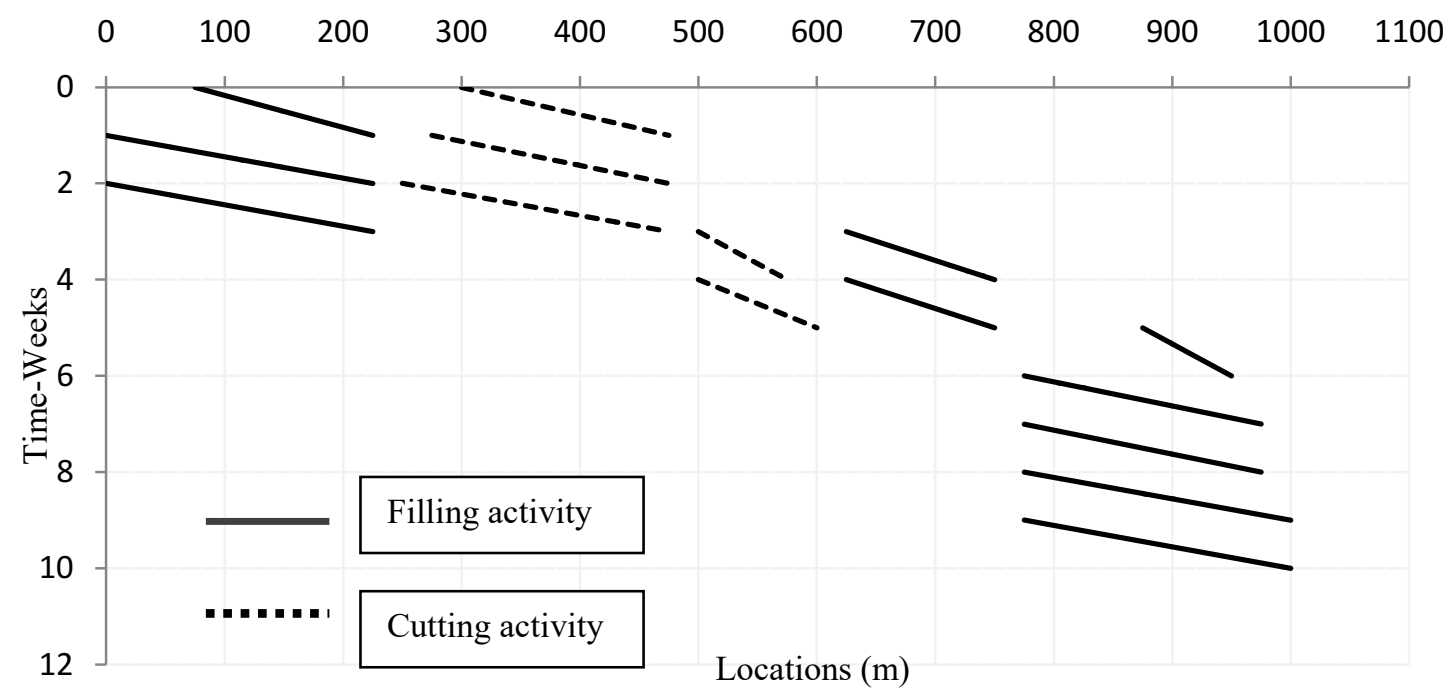

Figure 10b Snapshot of automatic generated time location plan of the road section using one set of equipment for filling and one set of equipment for cutting operation

This is the key achievement in terms of accuracy of earthwork planning tasks that should assist in resource planning and managing activities conflict. Hence, the time location plans for earthwork activities can be generated by incorporating the "variable" productivity and providing more accurate information of working locations. The time location plan also incorporated the site access points, different sets of equipment and soil characteristics aiming to provide accurate information construction schedule. This assists to plan and optimise the available resources and workspace at earthwork construction site throughout the earthwork operations in a road project.

The next section presents the result of sensitivity analysis to confirm the effectiveness of the developed model by analysing with "what if-scenarios" for different variables that affects the resource optimisation and improve on site productivity in earthwork operations. The construction industry survey revealed that site access points, types of equipment and soil characteristics are the critical factors affecting earthwork productivity.

\section{RESULTS OF SENSITIVITY ANALYSIS FOR DIFFERENT VARIABLES For the case of site access points (working length)}

The results presented in figure 11 show that total duration was 7 days for filling 1 and 2 sections while 3 days for cutting section -1 of earthwork operations, which is similar for access points 3 and 5 assuming that other variables and resources are constant. However, the total duration was 9 days for filling- $1 \& 2$ sections while 4 days for cutting-1 section of earthwork operations for six numbers of access points, which are higher than the smaller numbers of access points. 
Therefore, the above results conclude that lower number of access point is more economical, and reduces in resources wastage to complete the same quantity of earthwork in comparison to a higher number of the site access points for same sections in road construction projects.

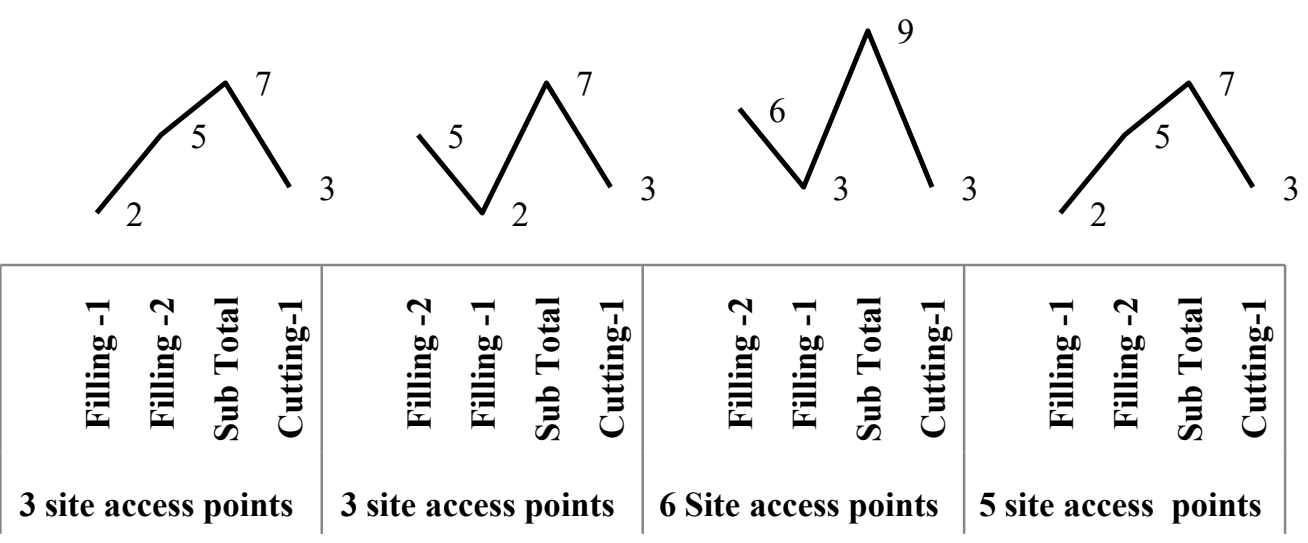

Figure 11 Sensitivity results on earthwork duration for different site access points

\section{For the cases of different types of equipment}

The results presented in figure 12 show that total duration was 35 days for filling $1 \&$ 2 sections and 18 days for cutting -1 section of earthwork operations at excavator type -1 (Exa). On other hand, total duration was 35 days for filling $1 \& 2$ sections and 14 days for cutting-1 section of earthwork operations at excavator type -2 (Exb) assuming other variables and resources are constant. However, the total duration was 34 days for filling- 1 \& 2 sections and 12 days for cutting -1 section when using excavator type -3 (Exc), and total duration was 26 days for filling $-1 \& 2$ sections and 9 days for cutting-1 section of earthwork operations using excavator type -4 (Exd). 

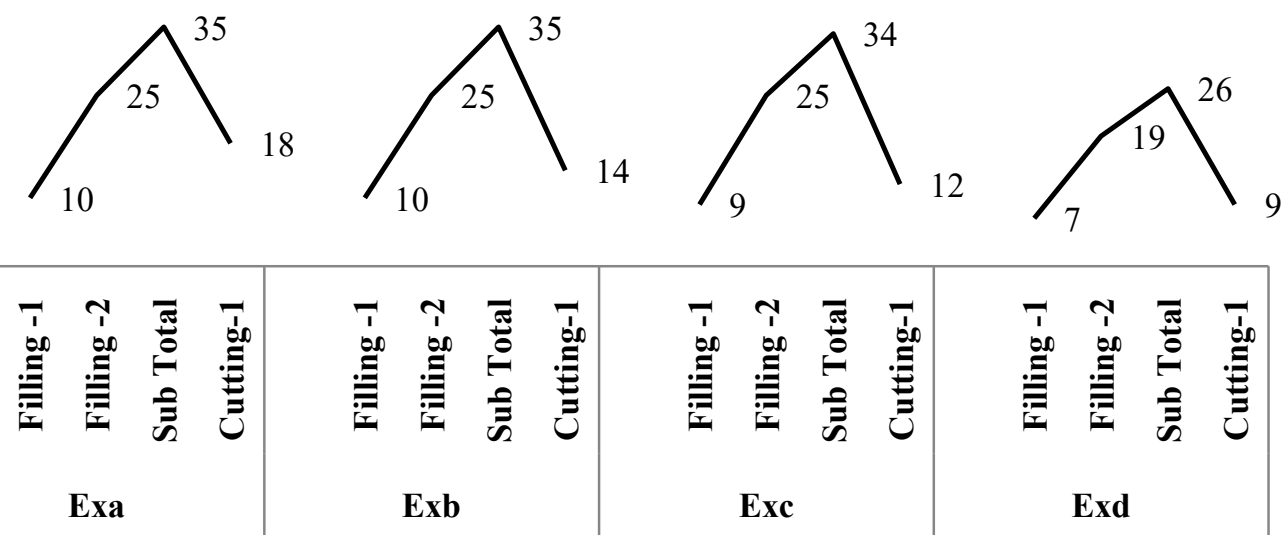

Figure 12 Sensitivity results on earthwork duration for different types of equipment

Therefore, the above results revealed that higher productive equipment is more economical by utilizing less time and minimum resources to complete the same quantity of earthwork in comparison to lower productive equipment assuming other conditions and factors remain same. Since, the production duration of earthwork is different for the different types of equipment; it will be worthy and logical to plan higher productive equipment if site conditions allow the earthwork operation so that idle time of heavy construction equipment can be reduced.

\section{For the case of different soil characteristics}

The results presented in figure 13 show that total duration was 40 days for filling sections $1 \& 2$ of earthwork operations since soil characteristics for filling sections were same throughout the road section. However, the total duration for the cutting section at different layers was different due to type of soil. The results show that duration of cutting-1 sections are 20,19,21 and 23 for different types of soil for sand, sand-clay, clay dry and clay wet respectively.

Therefore, the above results confirm that sand-clay soil at cutting section require minimum time in comparison with sand, clay-dry and clay-wet whereas clay-wet soil needs more time to complete the equal quantity of earthwork under similar site constraints in comparison to other soil characteristics. 


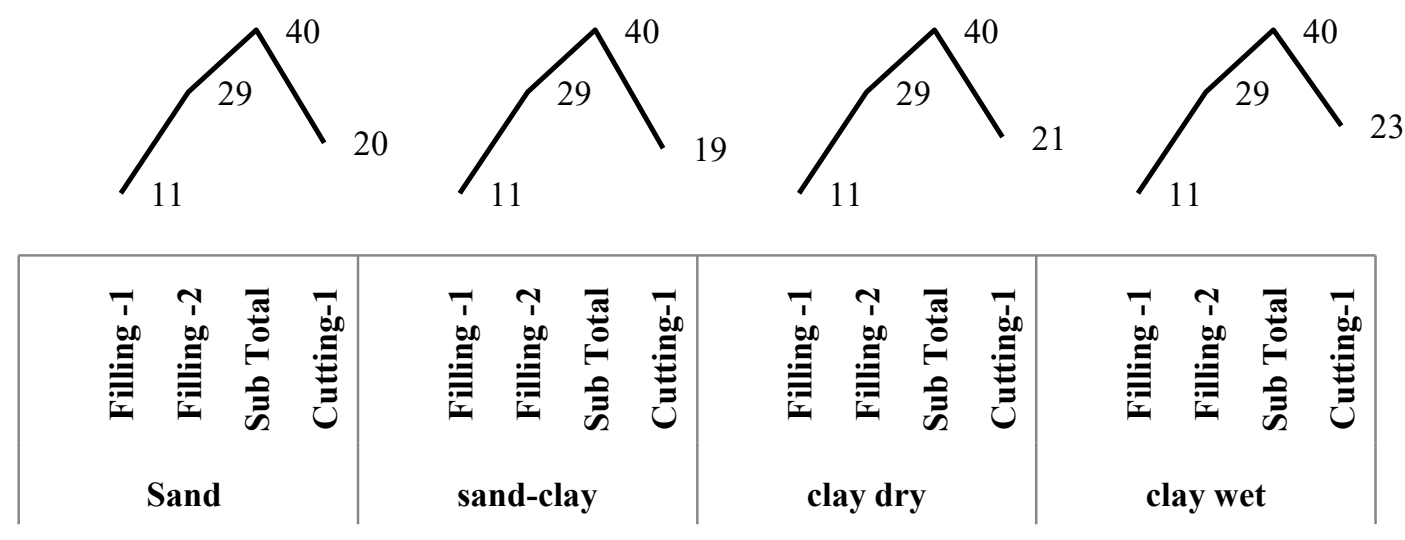

Figure 13 Sensitivity results on earthwork production time for different soil characteristics

It is concluded that the sensitivity analysis assist project planners and construction managers in simulation analysis with "what-if" scenarios for the production of construction schedule and resource planning taking into account of the different site conditions including types of equipment, soil characteristics and site access points (length of construction zones) in road construction projects.

The results of the sensitivity analysis confirm that three factors (site access points, types of equipment and soil characteristics) are the most critical variables, which have a direct impact on productivity and resource planning for earthwork operations in a road project. In the sensitivity analysis, the productivity of different types of equipment (for example; Exa, Exb, Exc, and Exd) were used to analyse the production time with "what if" scenarios under different soil conditions (for example, sand, sand-clay, clay dry and clay wet) and different working sections (site access points) along a road section. Therefore, project planners and construction managers need to analyse and simulate more carefully the sensitivity of the variables that affects productivity during the production of a construction schedule and resource planning in the earthwork operations at planning stage to reduce the adverse impact.

\section{Conclusions}

The prototype model developed in this paper is effective in automatically generating linear schedules (time location plans) and visualising the scheduling information of earthwork activities. The literature review revealed that existing scheduling methods do not provide the correct information of weekly locations and the industry survey conducted in the course of the research concluded that productivities of different equipment sets, soil characteristics, and site access points were the critical factors influencing the earthwork operations and resource planning. These factors are incorporated in the model to analyse their impact on production time, cost, and sequences of earthwork activities in respect of locations. The automatic generation of 
earthwork progress profiles, progress surfaces earthwork terrain, cost profiles, production cost s-curve and a time location plan are the main outputs of the prototype model.

The impact of critical factors such as changing the productivity of equipment, soil characteristics and site access points on scheduling processes could be investigated by the model using "what if scenarios" analysis. The key planning to knowledge is the automatic generation of a time location plan by incorporating variable factors influencing productivity and planning operations of earthworks . The functionalities and contributions of the model were demonstrated by case studies and sensitivity analysis. The paper concluded that the model is a valuable decision support tool that assists practitioners in identifying weekly locations and allocating construction equipment at correct locations. Consequently, the model is an effective tool in resource planning and communicating the scheduling information from location aspects in earthworks construction.

\section{REFERENCES}

Alkass, S. and Harris, F (1991), "Development of an integrated system for planning earthwork operations in road construction" Journal of Construction Engineering and Management, 9 (3), 263-289.

Askew, W. H., Al-Jibouri, S. H., Mawdesley, M. J. and Patterson, D. E. (2002), "Planning linear construction projects: automated method for the generation of earthwork activities", Automation in Construction, Vol. 11, 643 - 653.

Castro, S. and Dawood, N. (2009), "Automating road construction planning with a specific-domain simulation system", ITcon Vol. 14, p556-573. http://www.itcon.org/2009/36 (accessed 15 May 2010).

DynaRoad (2006), "DynaRoad: plan, schedule and control", http://www.dynaroad.fi/pages/index.php (accessed 15 May 2010).

Essa, S. M. (1987), "Earthwork allocations with non constant unit costs." Journal of Construction Engineering and Management", 113(1), pp 34-50.

Essa, S. M. (1988), "Earthwork allocations with linear unit costs" Journal of Construction Engineering and Management", 114(4), 641-655.

Garold, D. O., Samir, A. A. and Gregory, A. D. (2005), "Linear scheduling of highway project", Oklahoma Transportation Centre Research Project, OTC25.

Harmelink, D. J. and Yamin, R. A. (2000), "Development and application of linear scheduling techniques to highways construction projects", Technical report of FHWA/IN/JTRP-2000/21, Oct. 2000, pp 8-69.

Jayawardana, A. K. W. and Harris, F. C. (1990), "Further development of integer programming in earthwork optimisation", Journal of Construction Engineering and Management, 116 (1), pp. 18-34.

Johnston, D. W. (1981), "Linear Scheduling Method for Highway Construction", Journal of Construction Division, ASCE, 107 (2), pp. 247-261. 
Karimi S. M., Mousavi, S.J., Kaveh, A and Afshar, A (2006), "Fuzzy optimisation model for earthwork allocation with imprecise parameter", Journal of Construction Engineering and Management, ASCE, 133 (2) pp. 181-190

Kenley, R. and Seppanen, O. (2009), "Location based management of construction projects: part of a new typology for project scheduling methodologies", Proceedings of the 2009 winter simulation conference, pp. 2563-2570.

Kenley, R. and Seppanen, O. (2010), "Location based management for construction projects: planning, scheduling and control", First edition, Spon Press, Abingdon, UK.

Kim, S. and Rusell, J. S. (2003), "Framework for an intelligent earthwork system Part I system architecture", Automation in Construction, Vol. (13), PP 1-13.

Mattila, K. G. and Abraham, D. M. (1998), "Linear scheduling: past research efforts and future directions", Engineering, Construction and Architectural Management, Vol. 5 (3), PP 294- 303.

Mawdesley, M. J., Al-Jibouri, S. H., Askew, W. H. and Patterson, D. E. (2002), "A model for the automated generation of earthwork planning activities", Journal of Construction Innovation: Information, Process, and Management, Vol. 2(4) pp. 249-268.

Mayer, R. and Stark, R. (1981), "Earthmoving Logistic”, Journal of the Construction Division, ASCE, 107 (2), 297-312.

Son, J., Mattila, K. G. and Myers, D. S. (2005), "Determination of haul distance and direction in mass excavation", Journal of Construction Engineering and Management, ASCE, Vol. 131 (3), pp.302-309

TILOS (2009), "Linear Project: TILOS", http://www.tilos.org/software_en.html (accessed 15 May 2010). 